\title{
Rheology, fiber dispersion, and robust properties of Engineered Cementitious Composites
}

\author{
Mo $\mathbf{L i} \cdot$ Victor C. Li
}

Received: 6 April 2011/Accepted: 12 July 2012

(C) RILEM 2012

\begin{abstract}
The capability of processing robust Engineered Cementitious Composites (ECC) materials with consistent mechanical properties is crucial for gaining acceptance of this new construction material in various structural applications. ECC's tensile strainhardening behavior and magnitude of tensile strain capacity are closely associated with fiber dispersion uniformity, which determines the fiber bridging strength, complementary energy, critical flaw size and degree of multiple-crack saturation. This study investigates the correlation between the rheological parameters of ECC mortar before adding PVA fibers, dispersion of PVA fibers, and ECC composite tensile properties. The correlation between Marsh cone flow rate and plastic viscosity was established for ECC mortar, justifying the use of the Marsh cone as a simple rheology measurement and control method before fibers are added. An optimal range of Marsh cone flow rate was found that led to improved fiber dispersion uniformity and more consistent tensile
\end{abstract}

\section{Li}

Department of Civil and Environmental Engineering, University of Houston, N 132 Engineering Bldg 1, 4800

Calhoun Road, Houston, TX 77204-4003, USA

e-mail: moli@uh.edu

V. C. Li $(\bowtie)$

Department of Civil and Environmental Engineering, University of Michigan, 2350 Hayward Street, Ann Arbor, MI 48109-2125, USA

e-mail: vcli@umich.edu strain capacity in the composite. When coupled with the micromechanics based ingredient-tailoring methodology, this rheological control approach serves as an effective ECC fresh property design guide for achieving robust $\mathrm{ECC}$ composite hardening properties.

Keywords Engineered Cementitious Composites · Rheology · Fiber dispersion - Tensile strain capacity · Marsh cone flow rate $\cdot$ Plastic viscosity

\section{Introduction}

In the past decade, great strides have been made in the development and testing of Engineered Cementitious Composites (ECC), a class of high-performance fiberreinforced cementitious composites (HPFRCC) featuring high intrinsic tensile ductility and moderate fiber content [1]. ECC exhibits tensile strain-hardening behavior through multiple micro-cracking with self-controlled crack width, leading to fracture toughness similar to aluminum alloys [2]. Tensile strain capacity in the 3-5\% range, about 300-500 times that of concrete and fiber reinforced concrete (FRC), has been demonstrated in ECC materials using polyvinyl alcohol (PVA) fibers with fiber volume fraction at $2 \%$ [3]. It has been demonstrated experimentally that R/ECC structural members, such as beams [4], columns [5], walls [6], and connections [7] surpass 
normal R/C structural members in structural load carrying capacity, deformability, and energy absorption capacity under monotonic and reverse cyclic loading. Additionally, ECC's high tensile ductility, deformation compatibility with existing concrete, and self-controlled micro-crack width lead to its superior durability under various mechanical and environmental loading conditions such as fatigue, freezing and thawing, chloride exposure, and drying shrinkage [8-12]. ECC is emerging in full-scale structural applications in Europe, Japan, and the US [13-16].

The capability to process ECC materials with consistent mechanical properties is crucial for gaining acceptance of this new construction material in various structural applications. Variation in ECC tensile behavior, however, has been observed in laboratory small-scale and onsite large-scale production depending on the type of mixers, mixing procedure, local ingredients characteristics, and mixing personnel's experience. This undesirable feature is reflected in the variability of the measured material tensile strain capacity, ultimate tensile strength, and width and density of micro-cracks. Figure 1 shows an example of an extremely large variability in the tensile stress-strain curves of one ECC mix produced using a gravity mixer with capacity of $0.6 \mathrm{~m}^{3}$. Although the

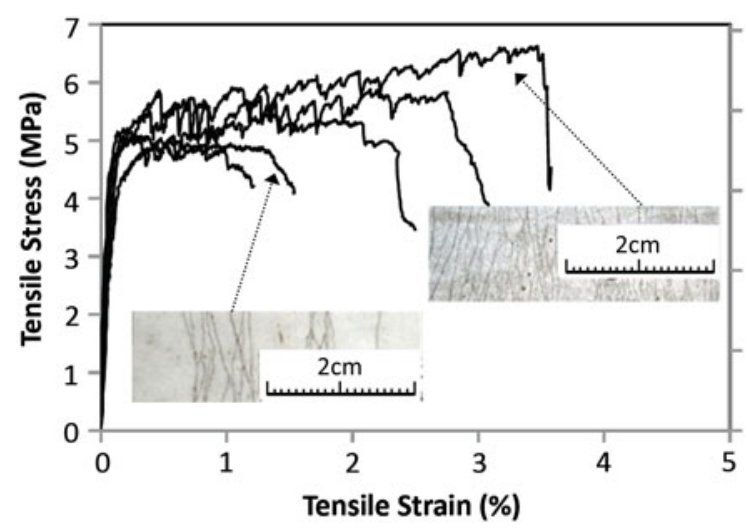

Fig. 1 An extreme case of variation in tensile stress versus strain curves of ECC with same mix proportion mixing proportion was identical, the specimens from different batches of mixing showed tensile strain capacity ranging from 0.6 to $3.4 \%$. Some specimens formed closely spaced "saturated" micro-cracks during the strain-hardening stage, and therefore had larger tensile strain capacity at peak load. Other specimens reached the tension-softening stage soon after a limited number of micro-cracks formed, leading to a lower tensile strain capacity. Albeit chosen to emphasize the potential large property variation, this example illustrates the need for an effective quality control methodology in ECC processing for consistent and optimized hardened properties.

The hypothesis is that the variation in ECC tensile ductility is mainly due to the influence of rheology during processing on the composite microstructure that governs ECC composite behavior. Notably, most ECCs utilize short, randomly distributed PVA fibers with a $2 \%$ volume fraction and properties specified in Table 1. During ECC mixing, fibers are added after the other ingredients, i.e. cementitious and pozzolanic ingredients, sand, water, and admixtures, are mixed and have achieved a consistent mortar state. The processing details such as mixer type, mixing speed, time and sequence, and mixing personnel's experience level can influence the rheological properties of the ECC mortar (ECC before adding fibers), which may strongly affect fiber dispersion uniformity, size distribution of entrapped air pores in the cementitious matrix, and bonding properties at the fiber/matrix interface in the hardened state. Additionally, although $2 \%$ PVA fibers are commonly used for ECC mixtures, ECC matrix ingredients from different sources or chosen for specific functions (e.g. high early strength [17]) may lead to alterations in ECC rheological properties and composite microstructure due to plausible changes in particle grain size and water absorption.

Published literature on the correlation between cementitious composite rheological properties and fiber volume or dispersion, has typically focused on rigid steel fibers. It has been shown that increasing

Table 1 Properties of REC 15 PVA fiber

\begin{tabular}{lllllll}
\hline $\begin{array}{l}\text { Fiber } \\
\text { type }\end{array}$ & $\begin{array}{l}\text { Nominal strength } \\
(\mathrm{MPa})\end{array}$ & $\begin{array}{l}\text { Apparent strength } \\
(\mathrm{MPa})\end{array}$ & $\begin{array}{l}\text { Fiber diameter } \\
(\mu \mathrm{m})\end{array}$ & $\begin{array}{l}\text { Fiber length } \\
(\mathrm{mm})\end{array}$ & $\begin{array}{l}\text { Young's modulus } \\
(\mathrm{GPa})\end{array}$ & $\begin{array}{l}\text { Elongation } \\
(\%)\end{array}$ \\
\hline REC15 & 1,620 & 1,092 & 39 & 12 & 42.8 & 6.0 \\
\hline
\end{tabular}


fiber volume fraction and aspect ratio decreases the workability of cementitious composite material [18-22]. Swamy and Mangat [23] observed that there was a critical volume content of fibers above which the concrete was not able to flow, even for initially very flowable cementitious matrices. The critical fiber volume content tends to decrease when the fiber aspect ratio increases [24, 25]. Bui et al. [26] and Kuder et al. [27] studied the influence of short steel fibers on the rheology of cementitious composites, and found that the yield stress and viscosity decreased until a critical volume faction of steel fibers was reached. The hypothesis was that at low steel fiber volumes (up to $1 \%$ ), the presence of stiff steel fibers during mixing help mechanically break down the mixture, leading to a decreased viscosity. At higher fiber volume fractions (2-4\%), the steel fiber interlocking dominates the flow behavior and leads to an increased viscosity. Ozyurt et al. [28] further found that fresh rheological properties affect segregation of steel fibers and mechanical properties of steel FRC. Standard deviation of the steel fiber contents (from the mean value) throughout the specimen decreases as viscosity increases. Boulekbache et al. [29] investigated the effect of matrix yield stress on the steel fiber distribution and orientation, using a translucent fluid matrix. The study showed that the rheology of concrete matrix influences the orientation and distribution of fibers, which subsequently influence the flexural behavior of the hardened materials. By applying a "rheology of paste model" that includes steel fibers in particle size distribution tailoring, Ferrar et al. [30] developed an effective model and tool for designing self-consolidating steel FRC with optimized rheological properties. Chung [31] assessed the degree of dispersion of carbon and steel fibers in cement mortar by measuring the volume electrical resistivity, and found that the degree of dispersion improved by use of silica fume, acrylic particle dispersion, methylcellulose solution, silane, and fiber surface treatment. Yang et al. [32] investigated the effects of fly ash type, water-binder ratio, and chemical admixtures on the fresh and hardened properties of ECC by means of design of experiments, but without directly assessing the effect on fiber dispersion and its role in composite behavior.

The above referenced literature suggests plausible correlations between mortar viscosity, fiber dispersion, and composite properties. It also suggests that the control of viscosity of the fresh mortar by adjusting the chemical or mineral admixtures and control of water/ binder ratio, may be an effective means to attain improved and robust hardened composite properties. For PVA fiber reinforced cementitious composites, including ECCs, the correlation between mortar viscosity, PVA fiber dispersion, and composite hardened properties have not been previously established. The objective of this paper is to establish these correlations explicitly for the first time, via a systematic experimental framework. Based on these correlations, an optimal range of ECC mortar viscosity is identified for the first time for achieving uniform PVA fiber dispersion. It is experimentally confirmed that robust composite properties can be attained through more uniform fiber dispersion, when the ECC mortar rheology is controlled to within this optimal range.

\section{Research significance}

Successful precasting of ECC structural elements and on-site construction projects using cast-in-place ECC rely on the capacity to produce the material with consistent quality. This consistency enhances structural reliability and reduces material waste by fully utilizing the material capacity in the structural design process. For the first time, this study systematically establishes the correlations between ECC matrix rheological properties, fiber dispersion, and composite tensile properties. It provides an effective approach to achieve robust ECC composite properties through control of the ECC mortar viscosity to within a target range. With this methodology, structural performance using ECC material can be realized with confidence.

\section{Influence of ECC rheology on microstructure and composite properties}

Tensile strain-hardening behavior of ECC is realized by tailoring the synergistic interaction between the fiber, matrix, and fiber/matrix interface based on micromechanics theory. As a fiber reinforced brittle mortar matrix composite, ECC's pseudo strain-hardening behavior is achieved through the formation of matrix multiple cracking [33-35] To ensure steadystate flat crack propagation, the crack tip toughness $J_{\text {tip }}$ must be less than the complementary energy $J_{b}^{\prime}$ 
(a)
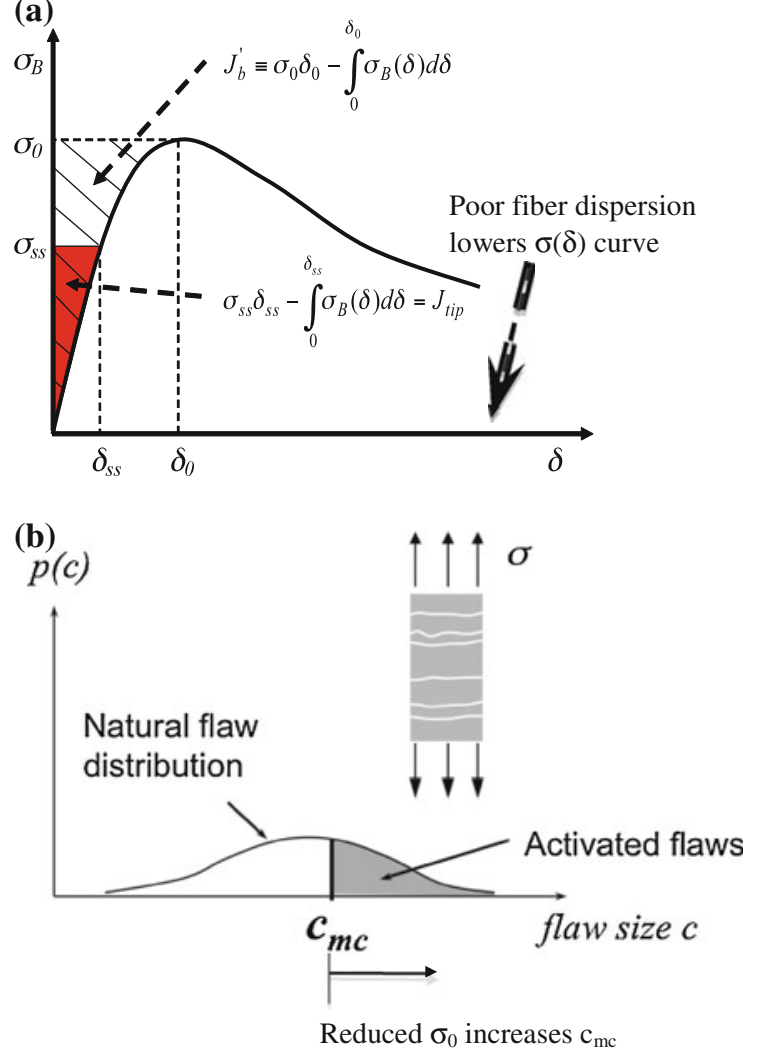

Fig. 2 Poor fiber dispersion leads to a lowered $\sigma(\delta)$ curve, $\sigma_{0}$ and $J_{b}^{\prime}$ and $\mathbf{b}$ increased critical flaw size $\mathrm{c}_{\mathrm{mc}}$

calculated from the fiber bridging stress $\sigma$ versus crack opening $\delta$ curve $[36,37]$ as illustrated in Fig. 2a.

$J_{\text {tip }} \leq \sigma_{0} \delta_{0}-\int_{0}^{\delta_{0}} \sigma(\delta) d \delta \equiv J_{b}^{\prime}$

$J_{\text {tip }}=\frac{K_{\mathrm{m}}^{2}}{E_{\mathrm{m}}}$

where $\sigma_{0}$ is the maximum bridging stress corresponding to the flat crack opening $\delta_{0}, K_{\mathrm{m}}$ is the matrix fracture toughness, and $E_{\mathrm{m}}$ is the matrix Young's modulus. The $\sigma(\delta)$ curve can be expressed as a function of micromechanics parameters, including fiber volume content $V_{\mathrm{f}}$, fiber diameter $d_{\mathrm{f}}$, fiber length $L_{\mathrm{f}}$, fiber Young's modulus $E_{\mathrm{f}}$, matrix Young's modulus $E_{\mathrm{m}}$, interface chemical bond $G_{\mathrm{d}}$, interface frictional bond $\tau_{0}$, and slip-hardening coefficient $\beta$.

Apart from the energy criterion (Eq. 1), another condition for pseudo strain-hardening is that the matrix tensile cracking strength $\sigma_{\mathrm{c}}$ must not exceed the maximum fiber bridging strength $\sigma_{0}$.

$$
\sigma_{\mathrm{c}}<\sigma_{0}
$$

where $\sigma_{\mathrm{c}}$ is determined by the matrix fracture toughness $K_{\mathrm{m}}$ and pre-existing internal flaw size $\mathrm{a}_{0}$. While the energy criterion governs the crack propagation mode, the strength-based criterion (Eq. 3) controls the initiation of crack propagation from material defect sites. Satisfying both Eqs. (1) and (3) is necessary to achieve ECC strain-hardening behavior; otherwise, the composite behaves as normal FRC with tensionsoftening behavior.

This study hypothesizes that the fresh rheology of ECC matrix directly governs fiber dispersion, which influences both the feasibility and density of multiplecracking. The $\sigma(\delta)$ curve, and in particular $\sigma_{0}$, strongly depend on the fiber distribution characteristics. For a specimen subjected to uniaxial tension, poor fiber distribution will lead to a reduced effective $V_{\mathrm{f}}$ at the "weakest" cross section within the specimen. The lower $V_{\mathrm{f}}$ will lead to a lower $\sigma_{0}$ so that premature exhaustion of the fiber bridging capacity results. As illustrated in Fig. 2a, non-uniform fiber dispersion will shift the $\sigma(\delta)$ curve downwards, thus reducing the complementary energy $J_{b}^{\prime}$ to less than $J_{\text {tip }}$. In this case, the steady-state criteria are violated and tension softening behavior results; ECC loses its ductile behavior and becomes a regular FRC material.

Even if the steady-state cracking criteria are satisfied and multiple-cracking is ensured, the high tensile strain capacity of ECC also depends on whether or not saturated formation of multiple micro-cracks takes place. The number of micro-cracks that can develop before reaching $\sigma_{0}$ is determined by: (i) the maximum fiber bridging stress $\sigma_{0}$, and (ii) the preexisting flaw size distribution and matrix fracture toughness. As illustrated in Fig. 2b, the maximum fiber bridging stress $\sigma_{0}$ at the "weakest" section with less fibers for crack bridging imposes a lower bound on critical flaw size $c_{m c}$ so that only those flaws larger than $\mathrm{c}_{\mathrm{mc}}$ can be activated during the multiple cracking process. Non-uniform fiber dispersion leads to a reduction of the value of $\sigma_{0}$ at the "weakest" section, which increases the critical flaw size $\mathrm{c}_{\mathrm{mc}}$. Therefore, less pre-existing flaws with sizes larger than $\mathrm{c}_{\mathrm{mc}}$ can be triggered and contribute to multiple cracking, resulting in relatively lower tensile strain capacity. 
Processing of ECC should achieve the ideal rheology in order to optimize fiber dispersion to a uniform random distribution state, thus minimizing the probability of creating "weak" sections with lower fiber content. By this means, the largest possible tensile strain capacity can be achieved through maximizing multiple-cracking behavior. In addition, when fibers are not uniformly dispersed, tensile properties determined using specimens made from the same batch would show variations. Figure 3 summarizes the interdependency of material processing and microstructure tailoring, and their convergence to produce ECC materials with desired combinations of properties and robustness.

\section{Experimental investigation}

The experimental program consists of three sets of investigations. First, the fresh viscosity and flowability of seven ECC mortar mixes (with the same mix design except for the different viscosity agent content) were measured using the Marsh cone flow test, mini-slump test and a rotational viscometer. Second, complete tensile stress-strain curves, including the tensile strain capacity, first cracking strength and ultimate tensile strength were measured using uniaxial tensile specimens made from the same seven ECC composite mixes (i.e. with fibers). Third, fiber dispersion at the final failure ("weakest") cross section of each tensile specimen was quantified using fluorescence imaging

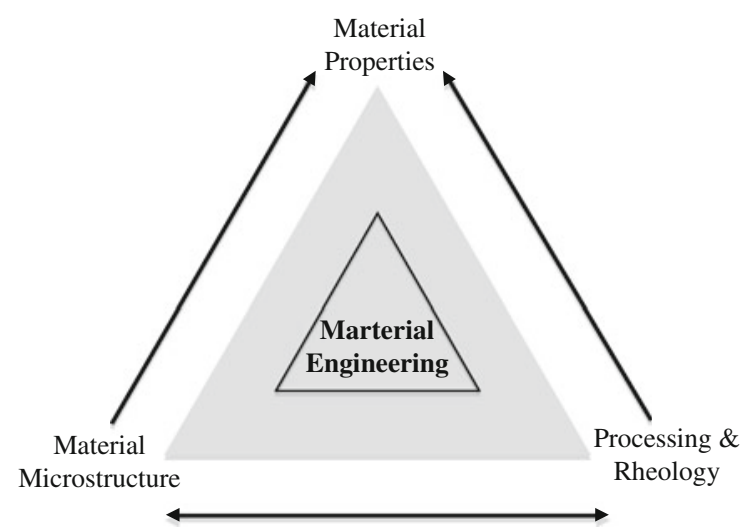

Fig. 3 ECC material engineering framework. In this study, the effect of rheology control of ECC mortar on composite material microstructure (e.g. fiber dispersion) and properties is emphasized technique. Based on these data sets, the relationships between ECC mortar fresh properties, composite tensile strain capacity, and fiber dispersion were established. The optimal range of fresh properties, defined as the viscosity of the ECC mortar that leads to most uniform fiber dispersion and tensile strain capacity in the composite, was then identified. Finally, a special version of ECC (a white colored pigmentable ECC) was processed and tested in uniaxial tension to verify the effectiveness of this approach. A flow chart of the experimental program is shown in Fig. 4.

\subsection{Materials}

Seven mixtures with the same mix proportion (Table 2) but with different viscosity agent content were produced. The mixtures were designed according to ECC micromechanics-based design theory to achieve tensile strain-hardening composite behavior. The binder system contained water, a polycarboxylate-based high range water reducer, Ordinary Portland Cement (OPC) Type I cement with Blaine surface area of $3,300 \mathrm{~cm}^{2} / \mathrm{g}$, ASTM standard Type F fly ash with mean grain size of $10-20 \mu \mathrm{m}$, and F-110 fine silica sand as fine aggregates with $250 \mu \mathrm{m}$ maximum grain size and $110 \mu \mathrm{m}$ mean grain size. The cementitious ingredients, silica sand, water and admixture together formed the ECC matrix with tailored crack tip toughness $J_{\text {tip }}$ and tensile cracking strength $\sigma_{\mathrm{c}}$ that satisfied Eqs. (1) and (3). The seven mixtures achieved increasing plastic viscosity by adding VMA (trade name V-MAR ${ }^{\circledR}$ ) with increase dosages of $0,0.01$, $0.015,0.02,0.025,0.03$ and $0.04 \%$ of cement weight.

PVA fibers were incorporated into the composite system at a volume fraction of $2 \%$. The PVA fibers were $12 \mathrm{~mm}$ long and $39 \mu \mathrm{m}$ in diameter, with nominal tensile strength of 1,600 MPa and density of $1,300 \mathrm{~kg} / \mathrm{m}^{3}$ (Table 1). The fiber surface was coated with oil ( $1.2 \%$ by weight) to control the fiber/matrix interfacial bond so that the complementary energy $J_{b}^{\prime}$ and the maximum fiber bridging stress $\sigma_{0}$ satisfy Eqs. (1) and (3) at the small fiber volume percentage of $2 \%$.

\subsection{Mixing, testing of fresh properties, and casting}

All mixtures were prepared using a $12 \mathrm{~L}$ capacity Hobart mixer, and followed the same mixing sequence, speed, and time under controlled room 




Fig. 4 Experimental program

Table 2 Mix proportion of ECCs

\begin{tabular}{llllllll}
\hline Mix $^{\mathrm{a}}$ & Cement & Silica sand & Fly ash & Water & Fiber, $\left(V_{\mathrm{f}}\right)$ & SP & VMA $(\%)$ \\
\hline ECC_x & $\begin{array}{l}1.0 \\
\text { Type I, ordinary }\end{array}$ & 0.8 & 1.2 & 0.66 & $2.0 \%$ & $0.013 \%$ & $\mathrm{x}$ \\
WHITE ECC_y & $\begin{array}{l}1.0 \\
\text { Type I, white }\end{array}$ & 0.5 & - & 0.31 & $2.0 \%$ & $0.3 \%$ & $\mathrm{y}$ \\
& & & & & & & \\
\hline
\end{tabular}

${ }^{a}$ Content of PVA fibers is expressed as volume fraction of the mix, while all the other ingredients are expressed as weight proportion of cement content. Seven mixes were investigated for ECC_x, with $\mathrm{x}=0,0.01,0.015,0.02,0.025,0.03$ and $0.04 \%$. Three mixes were investigated for WHITE ECC_y, with $\mathrm{y}=0,0.05,0.1 \%$

temperature $20 \pm 1{ }^{\circ} \mathrm{C}$ and relative humidity conditions $50 \pm 5 \%$ RH. Solid ingredients, including cement, fly ash, and silica sand, were first mixed at $100 \mathrm{rpm}$ for $1 \mathrm{~min}$. Water and chemical admixtures, including super plasticizer and VMA, were then added into the dry mixture and mixed at $150 \mathrm{rpm}$ for $3 \mathrm{~min}$ to produce a consistent and uniform ECC mortar (w/o PVA fiber).

Mortar is generally assumed to be a non-Newtonian fluid, and the Bingham model is often used to describe its rheology [38]. Other models include the Atzeni, Casson, Ellis, Erying, Herschel-Bulkley, RobertsonStiff, Sisko, Vom Berg, and Williamson [39]. According to the most commonly used Bingham model, fresh mortar must overcome a yield stress before it can flow. Once it starts to flow, shear stress increases linearly with an increase in strain rate, the slope of which defines the plastic viscosity. Therefore, plastic viscosity measures how easily the material can flow once the yield stress is overcome.

In this study, plastic viscosity was measured using a rotational viscometer as a direct method, and Marsh cone flow time as an indirect method of characterizing the fresh ECC mortar. Comparatively, the advantages of the indirect method are its simplicity and the portability of the device to mixing sites. The objective was to investigate whether the Marsh cone flow time correlates well with the plastic viscosity of ECC mortar measured by the rotational viscometer, such that the Marsh cone flow rate test can be adopted as a practical and reliable method for quality control during ECC processing on-site.

The fresh properties test equipment used in this study is shown in Fig. 5. A Viskomat-NT rotational viscometer [40] (Fig. 5a) was used to measure the plastic viscosity and yield stress of the ECC mortars at 
a controlled temperature of $20 \pm 1{ }^{\circ} \mathrm{C}$. The material was stirred at a rotation rate $N$, generating shear resistance of torque $T$. A series of data points of $T$ and $N$ were recorded by a computer. Through linear regression, the relative yield stress $g(\mathrm{~N}-\mathrm{mm})$ and relative plastic viscosity $h(\mathrm{~N}-\mathrm{mm} / \mathrm{rpm})$ can be determined [41, 42]:

$T=g+N h$

Relative plastic viscosity $(\mathrm{N}-\mathrm{mm} / \mathrm{rpm})$ can be converted to plastic viscosity (Pa.s) using a calibration liquid [43].

A Marsh cone (Fig. 5b), also called a "Marsh funnel", is a simple device for measuring viscosity according to the time it takes a known volume of liquid to flow from the bottom of the cone though a short tube $[44,45]$. In this test, a funnel was filled completely with ECC mortar and the bottom outlet was opened, allowing the mortar to start flowing. The Marsh cone flow time was determined as the elapsed time $(t)$ in seconds between opening the bottom outlet and when light first became visible at the bottom.

The mini-slump test measures the consistency of mortar, and its results are correlated with the yield stress. As shown in Fig. 5c the mini-slump cone has a top diameter of $70 \mathrm{~mm}$ (2.76 in.), a bottom diameter of $100 \mathrm{~mm}$ (3.94 in.), and a height of $60 \mathrm{~mm}$ (2.36 in.). The cone was placed in the center of a square piece of glass and filled with ECC mortar. The cone was then lifted up to allow the mortar to flow. Once the flowing stopped, the spread of the mortar was recorded as the average of the diameters measured along two diagonals.

Fig. 5 Rheology properties tests: a Viskomat NT rotational viscometer b Marsh cone flow rate test c Mini-slump test
After the rheological measurements of ECC mortar, another batch of the same mix was made following the same procedure, with the exception that fibers were added to the ECC mortar and mixed at $150 \mathrm{rpm}$ for an additional three minutes. The mixtures were then cast into tensile plate molds, in a direction that is perpendicular to the length $(228.6 \mathrm{~mm})$ and width $(76.2 \mathrm{~mm})$ of each specimen. No external vibration was applied. The mixtures flowed under gravity to fill in the molds, and were therefore considered self-compacting. The tensile plate molds were then covered with plastic sheets, and demolded after $24 \mathrm{~h}$. Finally, the specimens were moisture-cured in plastic bags at $95 \pm 5 \%$ $\mathrm{RH}$ and $20 \pm 1^{\circ} \mathrm{C}$ for 7 days, and air cured at $50 \pm 5 \% \mathrm{RH}$ and $20 \pm 1{ }^{\circ} \mathrm{C}$ for 21 days until the age of 28 days when uniaxial tension testing commenced. Five specimens were prepared for each mixture.

\subsection{Testing of hardened tensile properties}

Five specimens from each mixture at 28 days age were subjected to uniaxial tensile testing, considered the most convincing method to evaluate material strainhardening behavior [46]. Figure 6 illustrates the test setup and plate specimen dimensions $(228.6 \times$ $76.2 \times 12.7 \mathrm{~mm}$ ). Before testing, four aluminum plates were glued to the surfaces of the specimen at both ends to facilitate gripping. Tests were conducted using a $25 \mathrm{kN}$ capacity MTS machine under a displacement control rate of $0.0025 \mathrm{~mm} / \mathrm{s}$ to simulate a quasi-static loading condition. Two external LVDT displacement transducers were attached to the specimen surface with a gage length of $101.6 \mathrm{~mm}$ to (a)

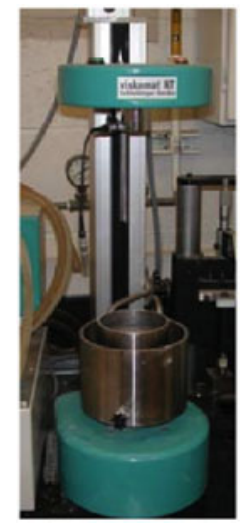

(b)

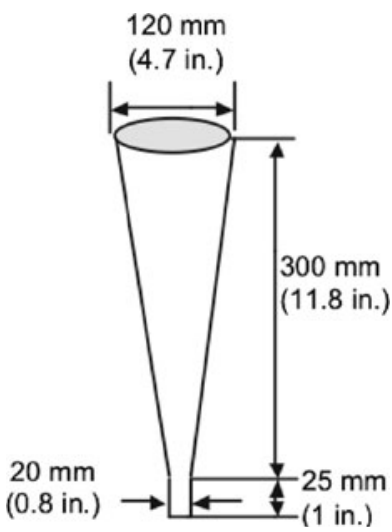

(c)

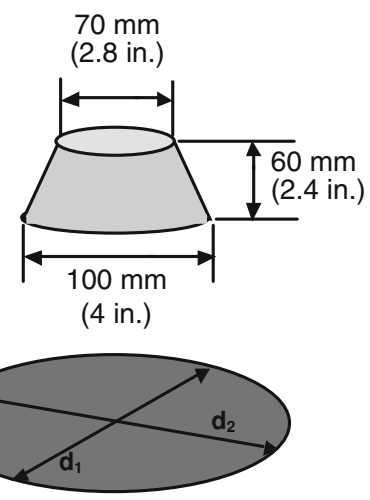


measure the displacement. The tensile stress-strain curve of each specimen was recorded.

\subsection{Measurement of fiber dispersion coefficient}

After the uniaxial tensile test, a $5 \mathrm{~mm}$-thick sample was cut from each tensile specimen at the final failure section, as shown in Fig. 6. This failure section is considered to be the "weakest section", where $\sigma_{0}$ is the lowest for the specimen. A fluorescence imaging technique was used to quantify the fiber distribution in this section. Compared to the optical microscopic method and the X-ray method, fluorescence technology has a very high level of sensitivity to detect bright organic fibers that fluoresce under UV lighting from the dark surrounding cementitious matrix with a low background signal [47-49].

Figure 7 illustrates the fluorescence imaging technique as well as the testing devices and setup. Without polishing, each of the 35 samples from seven mixtures was examined under a fluorescence microscope (TE300 Nikon). The light source of the fluorescence microscope was a mercury lamp, which generated light with a broad range of wavelengths. The sample was illuminated with light at a specific wavelength, which was absorbed by the fluorophores, causing them to emit longer wavelengths of light as the result of well-established physical phenomena described as fluorescence or phosphorescence. The emission of light through the fluorescence process is nearly simultaneous with the absorption of the excitation light due to less than a microsecond delay between photon absorption and emission [50]. The illumination light was separated from the much weaker emitted fluorescence by a UV filter. Through this process, fibers under the fluorescence microscope appeared brightly colored while the surrounding cementitious matrix appeared dark grey. The fluorescence image was then captured by a CCD camera (Hamamatsu 1394 ORCA-ER).

The whole cross sectional $76.2 \times 12.7 \mathrm{~mm}$ image of each sample, with $23005 \times 4186$ pixels, was constructed by connecting $105(21 \times 5)$ images with image processing software.

\section{Experimental results and discussion}

The measured material fresh and hardened properties are summarized in Table 3. The Marsh cone flow time of the seven ECC mortar mixtures is shown in Fig. 8a. Through adding an increased dosage of VMA, ECC mortar mixtures with the same material composition but a broad range of plastic viscosity were achieved. From ECC_0 (0 \% VMA content) to ECC_0.04\% (0.04\% VMA content), the Marsh cone flow time
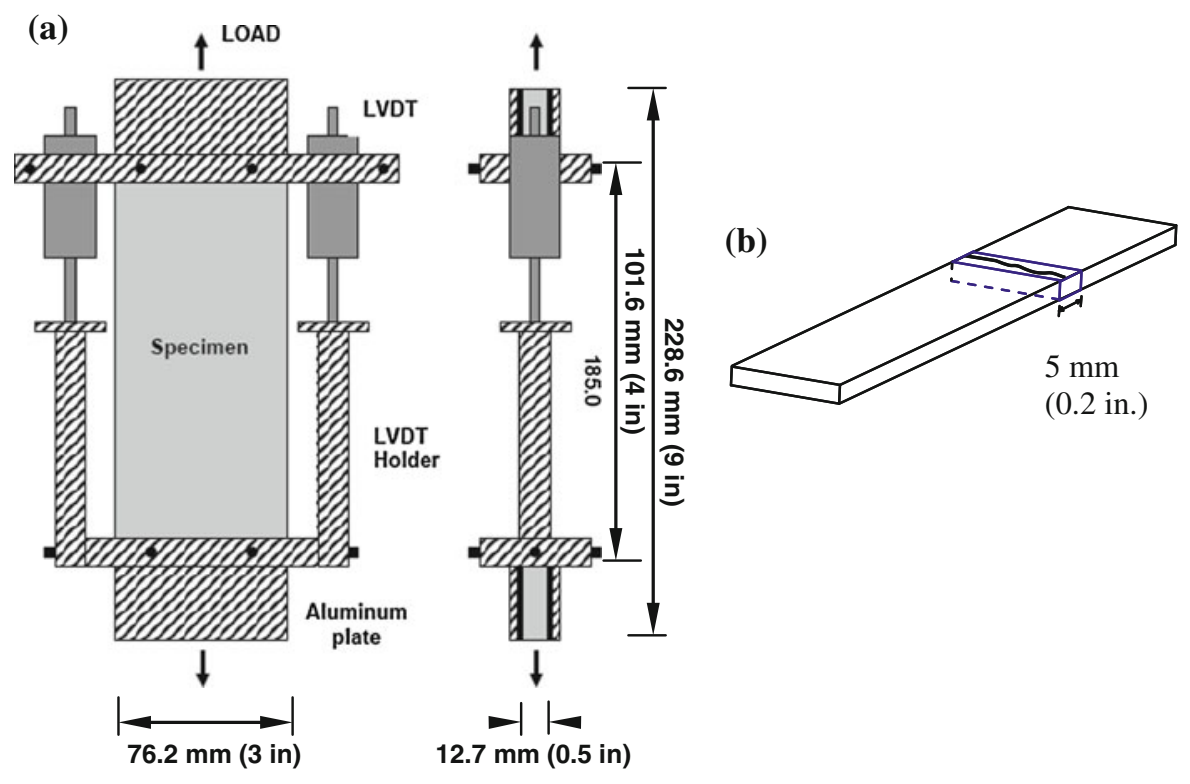

Fig. 6 Uniaxial tensile test: a test setup and specimen dimensions, b specimen preparation for measuring fiber dispersion at the final failure (weakest) section




Fig. 7 Fluorescence imaging technique and test setup

Table 3 Material fresh and hardened properties
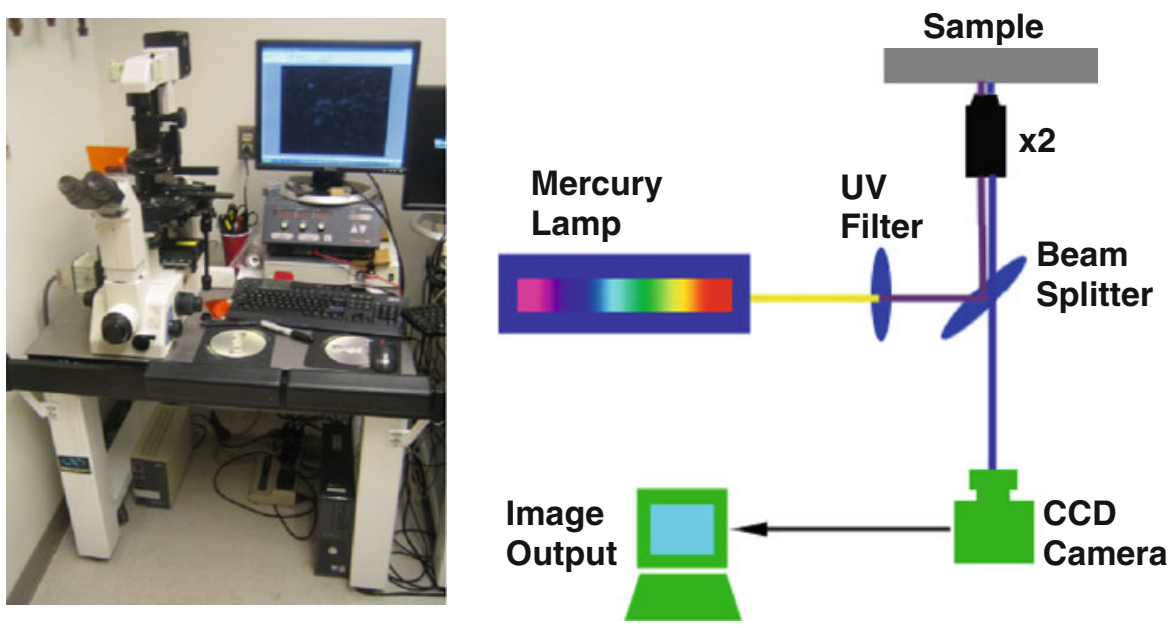

VMA_0

Marsh cone flow time (s)

Fiber dispersion coefficient

Tensile strain capacity (\%)

VMA_0.01

Marsh cone flow time (s)

Fiber dispersion coefficient

Tensile strain capacity (\%)

VMA_0.015

Marsh cone flow time (s)

Fiber dispersion coefficient

Tensile strain capacity (\%)

VMA_0.02

Marsh cone flow time (s)

Fiber dispersion coefficient

Tensile strain capacity (\%)

VMA_0.025

Marsh cone flow time (s)

Fiber dispersion coefficient

Tensile strain capacity (\%)

VMA_0.03

Marsh cone flow time (s)

Fiber dispersion coefficient

Tensile strain capacity (\%)

VMA_0.04

Marsh cone flow time (s)

Fiber dispersion coefficient

Tensile strain capacity $(\%)$

\section{9}

0.5

0.44

0.42

0.38

0.39

0.29

0.06

0.13

0.09

0.03

12

$\begin{array}{lllll}0.49 & 0.52 & 0.57 & 0.53 & 0.54\end{array}$

0.34

0.32

1.19

0.69

0.52

17

0.66

0.55

0.6

0.58

0.65

1.97

0.76

0.85

0.75

1.38

24

0.84

0.77

0.74

0.73

0.83

3.5

3.1

2.87

3.2

3.0

30

0.89

0.81

0.75

0.83

0.72

3.35

3.27

2.94

3.01

33

0.84

0.75

0.7

0.8

0.67

3.25

3.18

2.82

3.12

2.71

39

\begin{tabular}{lllll}
0.88 & 0.79 & 0.82 & 0.80 & 0.77 \\
3.33 & 3.27 & 3.30 & 2.83 & 3.23 \\
\hline
\end{tabular}

increased from 9 to $40 \mathrm{~s}$ due to increased plastic viscosity. The same trend was observed for the plastic viscosity measured using the rotational viscometer. A strong linear correlation $(R=0.95)$ was found in this study between the Marsh cone flow time and plastic viscosity, showing that the Marsh cone flow test 

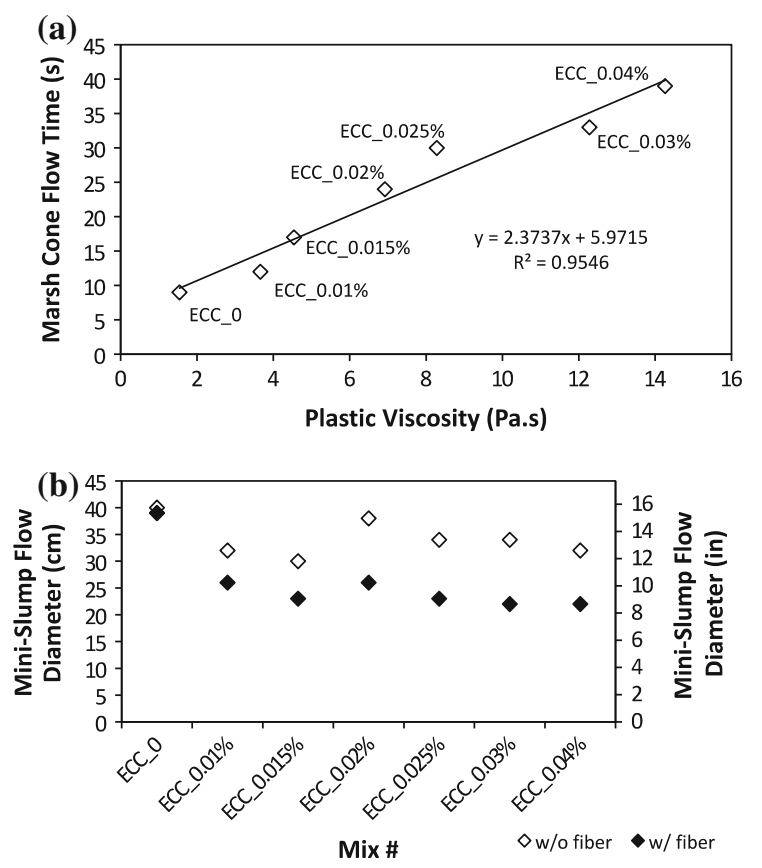

Fig. 8 Rheological properties of the seven ECC mixes: a Marsh cone flow time (before adding fibers) versus plastic viscosity, $\mathbf{b}$ mini-slump flow diameter (before and after adding fibers) of the seven ECC mixes

should be a reliable indirect method for onsite or laboratory viscosity measurement.

The mini-slump flow diameters of these seven mixes before and after adding fibers were measured (Fig. 8b). For the same mix, adding $2 \%$ fibers reduced the mini-slump flow diameter. Except for ECC_0.01\% that shows a drop in flow diameter from ECC_0, further increase in VMA content appeared to have a very slight or no effect on the mini-slump diameter, while the mix became more homogenous (less segregation and better fiber distribution). These test results indicate that for the specific range of mixtures in this study, including VMA can modify the plastic viscosity of ECC mortar without sacrificing the deformability of fresh ECC composite, as indicated by the non-changing mini-slump flow diameter.

Figure 9 shows the tensile stress-strain curves of the seven ECC mixtures from the uniaxial tensile test. For ECC_0, only one specimen shows slight strain-hardening behavior with $0.44 \%$ tensile strain capacity, while the other specimens show tension-softening behavior. Large variation exists not only in material tensile strain capacity, but also in the ultimate tensile strength. For ECC_0.01\%, although all of the specimens show tensile strain-hardening behavior, their tensile strain capacity is relatively low $(0.32-1.19 \%)$. Large variation in tensile strain capacity and ultimate tensile strength was also found in ECC_0.015 \%. While some specimens had improved tensile strain capacity up to $1.97 \%$, others had tensile strain capacity lower than $1 \%$. ECC_0.02\% exhibited more consistent tensile behavior as well as greatly improved tensile strain capacity, with an average value of $3.1 \%$. Specimens from ECC_0.025 \%, ECC_0.03 \%, and ECC_0.04 \% also all have tensile strain capacity around $3 \%$, and greatly improved consistency in tensile test data.

Figure 10a plots the mean value and standard error (as described by the error bar) of tensile strain capacity versus VMA/cement ratio. The data trend contains two parts: (i) From VMA/cement ratio of 0-0.02\%, tensile strain capacity increases while the relative standard error (the standard error divided by the mean) decreases. Note that the tensile strain capacity standard error of ECC_0 is lower than ECC $0.01 \%$ because of its lower mean value (standard error is an absolute value); (ii) From VMA/cement ratio of $0.02-0.04 \%$, there is no significant increase in tensile strain capacity. The standard and relative standard errors are both substantially smaller than those for mixes with smaller VMA dosage.

Figure $10 \mathrm{~b}$ shows the mean value and standard error (as described by the error bar) of tensile strength versus VMA/cement ratio. Again the trend contains two parts: (i) From VMA/cement ratio of $0-0.02 \%$, tensile strength increases while the standard error decreases; (ii) From a VMA/cement ratio of 0.025-0.04 \%, tensile strength decreases while the standard error remains low. Microscopy of the failure section revealed that bigger air pores were entrapped during processing in ECC_0.04\% compared with other mixes due to a larger plastic viscosity. This effect, combined with less area of net cross section available for fiber bridging, resulted in the lowered first-cracking strength and ultimate tensile strength of ECC_0.04\%. Future research is needed for detailed study of the effect of plastic viscosity on ECC pore structure and tensile behavior.

Figure 10a, b together suggest an optimal VMA/ Cement Ratio of $0.02 \%$ for maximizing the composite tensile strain capacity without reducing the tensile strength, for the specific mix design in this study.

Figure 11 shows the assembled fluorescence image of the whole cross section of a sample specimen. Additional images can be found in $\mathrm{Li}$ [51]. Image processing 
Fig. 9 Tensile stress versus strain curves of ECC with different VMA content as weight proportion of cement content: a no VMA

b $0.01 \%$ VMA c $0.015 \%$

d $0.02 \%$ e $0.025 \%$

f $0.03 \% \mathbf{g ~} 0.04 \%$


software was used to increase the contrast of the image to better reveal the fibers. The whole image was then divided into $5 \times 21$ unit areas, and the number of fibers per unit were counted. The fiber dispersion uniformity of the whole cross section was quantified by a fiber dispersion coefficient, which expresses the deviation of the number of fibers in a unit area from the average number of fibers. The fiber dispersion coefficient $\alpha$ is calculated using Eqs. (5) and (6) [39]:
$\Psi(x)=\sqrt{\frac{\sum\left(x_{i}-\bar{x}\right)^{2}}{n}} / \bar{x}$

$\alpha=\exp [-\Psi(x)]$

where $\psi(x)$ is the coefficient of variation, $x_{i}$ is the number of fibers in the unit area $i, \bar{x}$ is the average number of fibers in each unit area, and $n$ is the number of unit area. $\alpha$ equals to 1 for uniform fiber dispersion, 

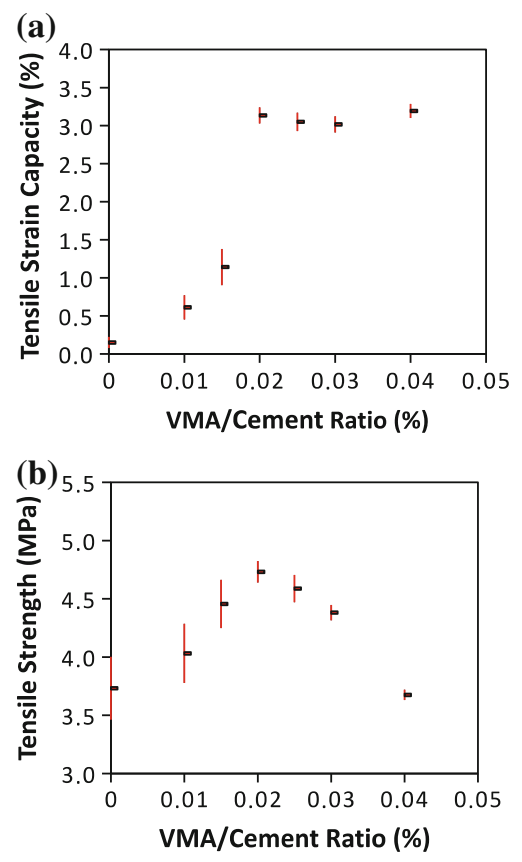

Fig. 10 a Tensile strain capacity versus VMA/cement ratio, b tensile strength versus VMA/cement ratio (vertical bars indicate standard error of data)

and approaches 0 when the coefficient of variation of fiber dispersion becomes larger. The fluorescence imaging technique effectively quantifies the dispersion uniformity of short discontinuous PVA fibers within a cementitious matrix. Fiber dispersion coefficient for the seven mixes with different amount of VMA was found to range from 0.29 to 0.89 .

Figure 12 summarizes the relationships between the Marsh cone flow rate of fresh ECC mortar before adding fibers, fiber dispersion, and hardened tensile strain capacity of ECC after adding fibers. A strong positive correlation is found between the fiber dispersion coefficient and composite tensile strain capacity (Fig. 12a). This observation validates the concept discussed earlier that when the fibers are more- uniformly distributed in an ECC specimen, the fiber bridging capacity $\sigma_{0}$ at the "weakest" section is larger, leading to a smaller critical flaw size $\mathrm{c}_{\mathrm{cm}}$. Therefore, more pre-existing flaws with size larger than $\mathrm{c}_{\mathrm{cm}}$ can be activated to form microcracks before the fiber bridging capacity at the "weakest" section is exhausted, resulting in a larger composite tensile strain capacity. Fiber uniformity as quantified by the fiber dispersion coefficient was found to have a strong effect on ECC tensile strain capacity. A lower fiber dispersion coefficient not only reduces ECC tensile strain capacity and ultimate tensile strength, but also increases the variability in both properties. A very low value for the fiber dispersion coefficient can switch ECC from a strain-hardening material to a tensionsoftening material.

Figure $12 \mathrm{~b}$ also shows that the fiber dispersion coefficient increases with Marsh cone flow time in ECC mortar. This increasing trend reaches a plateau after the Marsh cone flow time reaches $24 \mathrm{~s}$. At the Marsh cone flow time of $39 \mathrm{~s}$, a reduction in the first cracking strength and ultimate tensile strength was found despite a high value for the fiber dispersion coefficient (also see Fig. 9). This means that there exists an "optimal" range of Marsh cone flow time between 24 and $33 \mathrm{~s}$ for desired good fiber distribution, but without the attendant larger air voids at still higher flow time (or higher viscosity) as discussed earlier. This Marsh cone flow time versus fiber dispersion coefficient relation can be used as a guideline for rheology control during ECC processing to achieve close-to-uniform fiber dispersion.

It should be noted that mortar from different versions of ECC can have different original plastic viscosities (before viscosity control) at fresh state due to variation in ingredients and composition. While an optimal VMA dosage of $0.02-0.03 \%$ is suggested in this study for a particular mix, it may not apply to other ECC mixes. In fact, it is the optimal range of viscosity

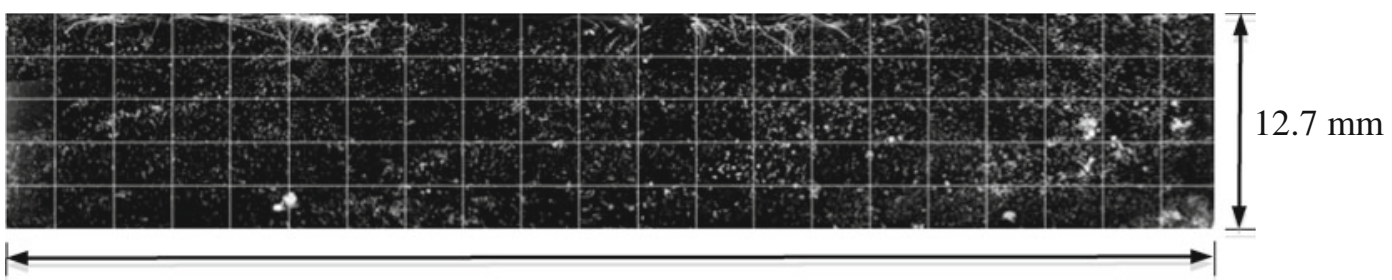

$76.2 \mathrm{~mm}$

Fig. 11 Fluorescence image of a sample specimen 

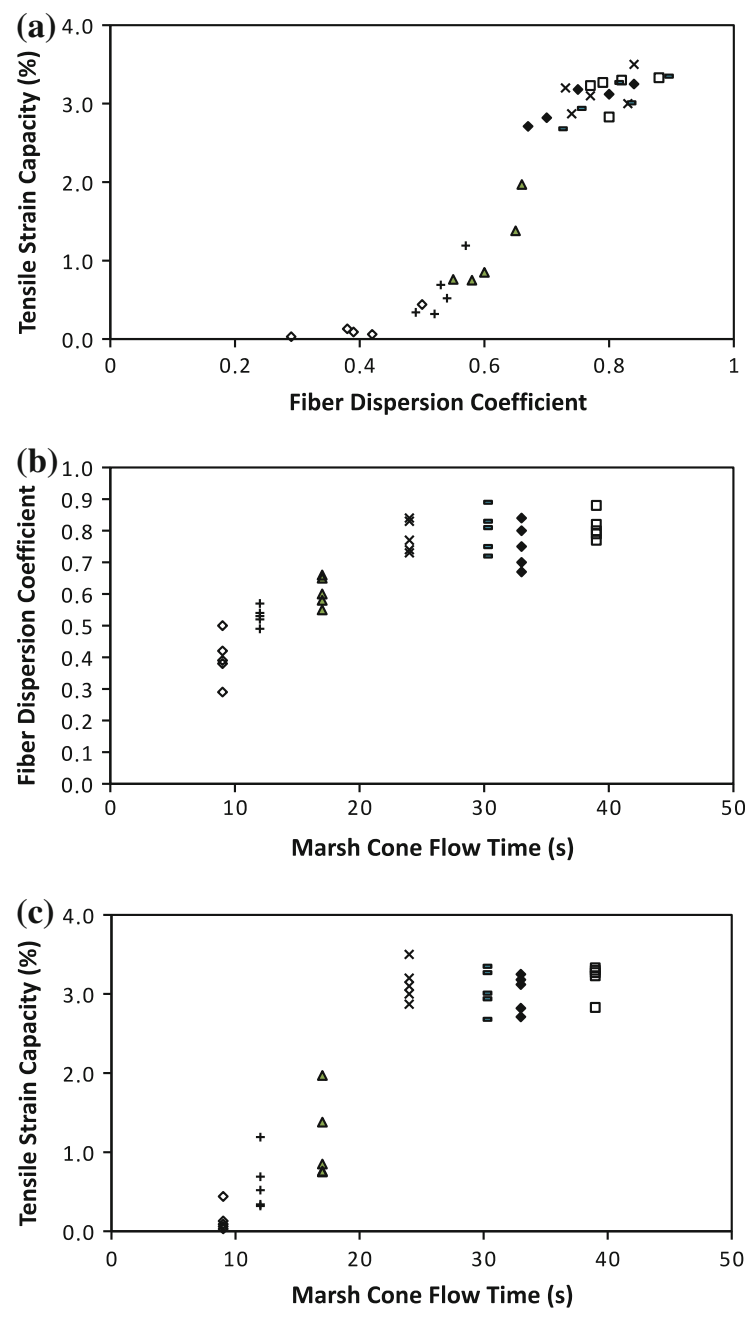

Fig. 12 Correlations between a tensile strain capacity and fiber dispersion coefficient, $\mathbf{b}$ fiber dispersion coefficient and Marsh cone flow time, and $\mathbf{c}$ tensile strain capacity and Marsh cone flow time

(quantified by Marsh cone flow time) that governs fiber dispersion, which should not depend on the difference in mixes as long as fiber type, content and dimensions are fixed. For most of the ECC mixtures, PVA fibers with the same dimensions at 2 vol\% are used, meaning that the optimal range of viscosity identified in this study can be generally applied. In this sense, addition of various dosages of VMA, together with other potential viscosity control methods (e.g. modifying ingredient particle size distribution, adjusting water/cement ratio, using super plasticizer), are only tools to achieve the objective of controlling viscosity within the identified optimal range.
Figure 12c shows the effect of ECC mortar Marsh cone flow rate on tensile strain capacity. Due to the strong positive correlation between tensile strain capacity and the fiber dispersion coefficient, the effect of Marsh cone flow time on tensile strain capacity is similar to its effect on the fiber dispersion coefficient. Tensile strain capacity increases with Marsh cone flow time, and reaches a plateau at $24 \mathrm{~s}$. This trend indicates that by controlling ECC mortar plastic viscosity so that its Marsh cone flow time falls into the range between 24 and $33 \mathrm{~s}$ before adding fibers, the hardened ECC material can achieve maximum tensile strain capacity as originally designed, based on micromechanics tools which assume fiber dispersion uniformity.

In summary, ECC mortar plastic viscosity is established experimentally as a fundamental rheological parameter that affects dispersion of PVA fibers in ECC mixes and ECC composite behavior. An ECC mortar with low plastic viscosity and Marsh cone flow time tends to have poorly distributed fibers, due to the lower shear force generated during mixing. Increasing plastic viscosity of ECC mortar improves fiber dispersion, because a higher shear force becomes available to distribute the PVA fibers. However, the improvement reaches a plateau once the higher plastic viscosity leads to larger size and amount of entrapped air pores, resulting in a lower net cross section area as well as lower fiber content at the "weakest" cross section. Therefore, an optimal range of plastic viscosity (i.e. optimal Marsh cone flow time) exists, which can be used to guide ECC rheology control during processing before fibers are added.

\section{Rheology control concept and case study}

Once the correlations between ECC mortar Marsh cone flow rate, fiber dispersion, and ECC tensile strain capacity were established, Fig. $12 \mathrm{~b}$ became available as a guideline to control the plastic viscosity of general ECC mortar before adding fibers so that maximized fiber dispersion and tensile strain capacity can be achieved. Plastic viscosity is indirectly quantified as the Marsh cone flow time (in seconds) in this figure, and the fiber dispersion coefficient is strongly correlated with tensile strain capacity. While the rheology control methodology was demonstrated using an ECC of the composition given in Table 2 (ECC_x), the methodology itself is general and can be applied to 
Fig. 13 Effect of rheology control on tensile stressstrain relation of WHITEECC: a before rheology control, $\mathbf{b}$ after adding VMA at $0.05 \%$ of cement content so that March Cone flow time was increased from 12 to $28 \mathrm{~s}$, $\mathbf{c}$ after adding VMA at $0.1 \%$ of cement content so that March Cone flow time was further increased to $38 \mathrm{~s}$

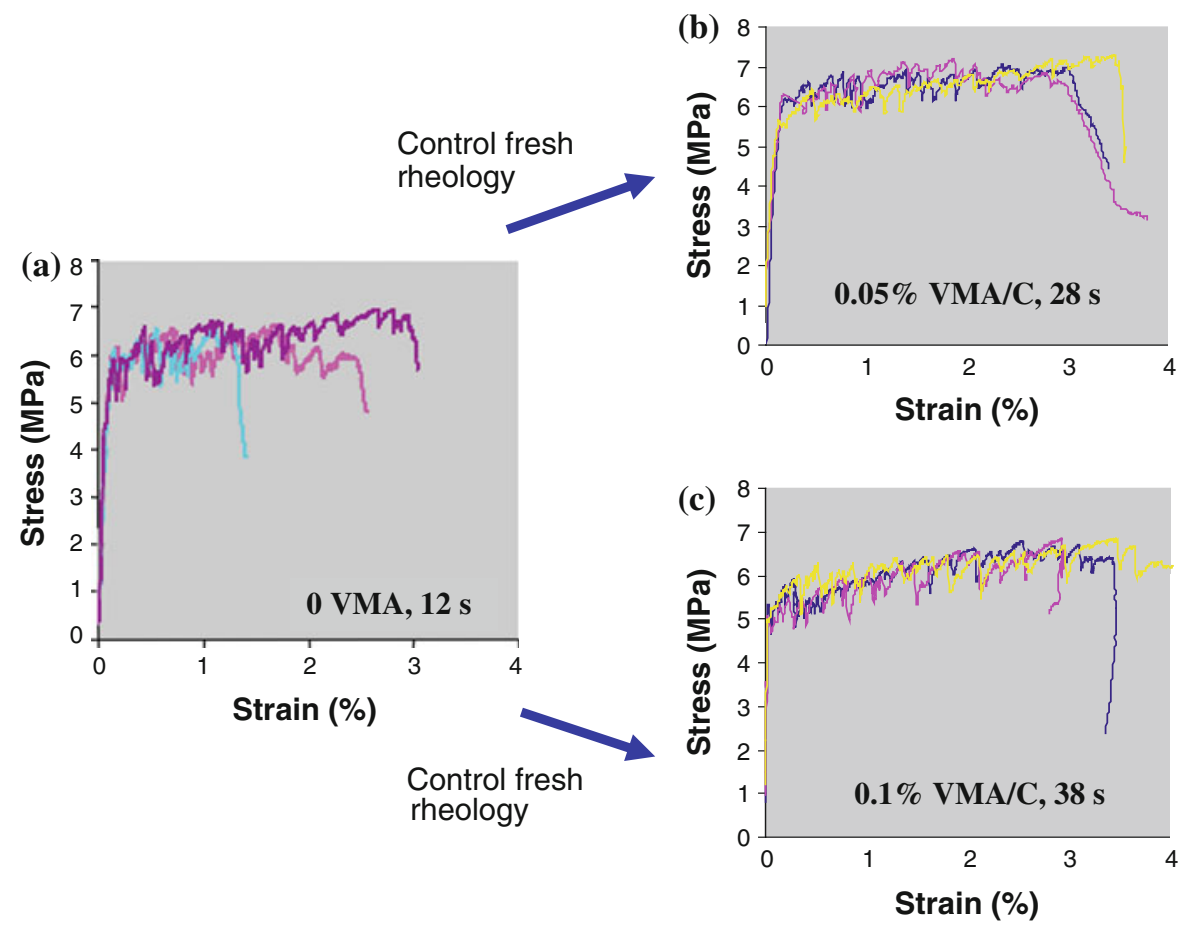

other ECC compositions. This concept is illustrated with a case study of a newly developed pigmentable white colored ECC [52] for architectural applications, as described below.

WHITE ECC has the mix proportions shown in Table 2 (WHITE ECC_y). This material was developed based on ECC strain-hardening theory, but is different from the ECC used to establish the rheology control methodology in terms of mix proportion and cement type. WHITE ECC contains Type I white cement instead of Type I ordinary Portland cement. Also, fly ash was deliberately removed in its mix design to avoid the darker grayish color. No VMA was used in this initial mix design. Using white cement and eliminating fly ash both result in a lower plastic viscosity of the mortar of WHITE ECC, making it challenging to achieve robust composite properties due to the observed tendency of fiber clumping during mixing. As shown in Fig. 13a, tests on three specimens of WHITE ECC without rheology control showed large variation in tensile properties, with tensile strain capacity ranging from 1.1 to $2.7 \%$.

To conduct rheology control on WHITE ECC, the Marsh cone flow rate test was performed on WHITE ECC mortar. Without any VMA, the Marsh cone flow rate for this mix was experimentally determined to be $12 \mathrm{~s}$, corresponding to a fiber dispersion coefficient around 0.53 based on Fig. 12b. This indicates that the fiber dispersion in this material was relatively poor. By adding VMA at a dosage of $0.05 \%$ cement content, the Marsh cone flow rate of WHITE ECC mortar was increased to $28 \mathrm{~s}$, corresponding to a fiber dispersion coefficient of around 0.8 (Fig. 12b). As shown in Fig. $13 \mathrm{~b}$, this method greatly improved the average tensile strain capacity of WHITE-ECC from 2 to $3 \%$, and reduced the variation in tensile properties. Adding more VMA, at a dosage of $0.1 \%$ of cement content, brought the Marsh cone flow rate up to $38 \mathrm{~s}$, which was close to the upper bound of the optimal range of Marsh cone flow time. Tensile test results (Fig. 13c) again showed greatly improved average tensile strain capacity as well as reduced variation. However, the first cracking strength and ultimate tensile strength were slightly reduced due to the higher value of plastic viscosity and likely entrapment of air. For this WHITE ECC mix, therefore, the addition of VMA at $0.05 \%$ of cement content leads to a plastic viscosity that falls within the optimal range of Marsh cone flow time. This VMA amount is more than twice the optimal amount recommended for the ECC mix discussed earlier 
(Table 2,ECC_0), due to the substantially lower starting plastic viscosity of the WHITE-ECC mortar mix.

This case study verified the effectiveness of the rheology control methodology. This methodology can be used for rheology control of any fresh ECC mortar before adding fibers in order to achieve maximum fiber dispersion uniformity and composite tensile strain capacity. The above findings reiterate the fact that the optimal amount of VMA varies for different ECC mix compositions. However, the optimal plastic viscosity (or Marsh cone flow rate) is a universal parameter as long as the same fiber type, content and dimensions are employed in preparing the ECCs.

\section{Conclusions}

Within this work, a simple and practical quality control method for enhancing ECC fiber dispersion uniformity and tensile property consistency was developed. This study systematically established the strong correlation between the ECC mortar plastic viscosity, fiber dispersion and composite tensile properties. This is the first time that fiber dispersion has been directly and quantitatively correlated with deliberate viscosity control for optimal composite tensile capacity performance.

An optimal range of plastic viscosity was revealed in this study, which can be used to guide ECC rheology control during processing before fibers are added. The simple Marsh cone flow test can serve as a reliable indirect method for onsite or laboratory viscosity measurement of ECC mortar. It should be noted that the optimal Marsh cone flow time between 24 and $33 \mathrm{~s}$ identified in this study only applies to ECCs containing 2 vol\% of PVA fibers with characteristics specified in Table 1, and to the mixing procedure and the mixer type (i.e. force-based mixer) specified in this study. For example, when a gravity-based truck mixer is involved, a higher range of optimal plastic viscosity or Marsh cone flow time is expected to generate enough shear force to uniformly disperse the PVA fibers. Such optimal ranges of plastic viscosity for gravity-based truck mixing and other types of mixing need to be established in future studies. Nonetheless, the strong correlation between plastic viscosity, PVA fiber dispersion and ECC composite behavior should always exist.

This study demonstrated that for ECC to achieve robust tensile strain-hardening behavior with designed tensile ductility, micromechanical material design should be combined with controlled material rheology during processing.

Acknowledgments The authors would like to thank the Michigan Department of Transportation and the U.S. National Science Foundation MUSES (Materials Use: Science, Engineering, and Society) Grant (CMS-0223971) and Metamorphix Global, Inc. for partially funding this research. The authors would also like to thank Professor Shuichi Takayama and Dr. Hao Chen at the University of Michigan Department of Biomedical Engineering for their helpful discussions on florescence microscopy.

\section{References}

1. Li VC (2007) Integrated structures and materials design. RILEM J Mater Struct 40(4):387-396

2. Maalej M, Hashida T, Li VC (1995) Effect of fiber volume fraction on the off-crack plane energy in strain-hardening engineered cementitious composites. J Am Ceram Soc 78(12):3369-3375

3. Li VC, Wu C, Wang S, Ogawa A, Saito T (2002) Interface tailoring for strain-hardening polyvinyl alcohol-engineered cementitious composites (PVA-ECC). ACI Mater J 99(5):463-472

4. Li VC, Wang S (2002) Flexural behavior of GFRP reinforced engineered cementitious composites beams. ACI Mater J 99(1):11-21

5. Fischer G, Li VC (2002) Effect of matrix ductility on deformation behavior of steel reinforced ECC flexural members under reversed cyclic loading conditions. ACI Struct J 99(6):781-790

6. Kesner K, Billington SL (2002) Experimental response of precast infill panels made with DFRCC. DFRCC-2002 International Workshop. Takayama, Japan, pp 289-298

7. Parra-Montesinos G, Wight JK (2000) Seismic response of exterior RC column-to-steel beam connections. J Struct Eng 126(10):1113-1121

8. Li VC, Li M (2008) Durability performance of ductile concrete structures. Proceedings of the 8 th international conference on creep, shrinkage and durability of concrete and concrete structures, Ise-Shima, Japan, pp 761-768

9. Sahmaran M, Li M, Li VC (2007) Transport properties of engineered cementitious composites under chloride exposure. ACI Mater J 104(6):604-611

10. Li M, Li VC (2009) Influence of material ductility on the performance of concrete repair. ACI Mater J 106(5): $419-428$

11. Li M, Li VC (2011) Cracking and healing of engineered cementitious composites under chloride environment. ACI Mater J 108(3):333-340

12. Li VC, Van Zijl GPAG, Wittmann F (2010) Durability of strain-hardening fibre-reinforced cement-based composites state of the art report, p 139

13. Li VC, Li M, Lepech M (2006) High performance material for rapid durable repair of bridges and structures. Michigan DOT Report RC-1484 
14. Kunieda M, Rokugo K (2006) Recent progress on HPFRCC in Japan. J Adv Concr Tech 4(1):19-33

15. Lepech MD, Li VC (2009) Application of ECC for bridge deck link slabs. RILEM J Mater Struct 42(9):1185-1195

16. Li VC, Fischer G, Lepech M (2009) Shotcreting with ECC. In: Kusterle W (ed) Proceedings CD, Spritzbeton-Tagung, Austria

17. Li M, Li VC (2011) High-early-strength engineered cementitious composites for fast, durable concrete repair: material properties. ACI Mater J 108(1):3-12

18. Hughes BP, Fattuhi NI (1976) The workability of steelfiber-reinforced concrete. Mag Concr Res 28(9):157-161

19. Rossi P (1992) Mechanical behavior of metal-fibre reinforced concretes. Cem Concr Compos 14(1):3-16

20. Grunewald S (2004) Performance-based design of selfcompacting fiber reinforced concrete. PhD Thesis. Section of Structuring and Building Engineering, Delft University of Technology, Netherlands

21. Dhonde HB, Mo YL, Hsu TTC, Vogel J (2007) Fresh and hardened properties of self-consolidating fiber-reinforced concrete. ACI Mater J 104(5):491-500

22. Martinie L, Rossi P, Roussel N (2010) Rheology of fiber reinforced cementitious materials: classification and prediction. Cem Concr Res 40:226-234

23. Swamy RN, Mangat PS (1974) Influence of fiber-aggregate interaction on some properties of steel fiber reinforced concrete. Mater Struct 7(41):307-314

24. Banfill PFG, Starrs G, Derruau G, McCarter WJ, Chrisp TM (2006) Rheology of low carbon fiber content reinforced cement mortar. Cem Concr Compos 28(9):773-780

25. Markovic I (2006) High-performance hybrid-fiber concrete: development and utilization. PhD Thesis, Department of Underground Infrastructure, Delft University of Technology

26. Bui VK, Geiker MR, Shah SP (2003) Rheology of fiber-reinforced cementitious materials. In: Conference of High performance fiber-reinforced cement composites (HPFRCC4), Springer, Netherlands, pp 221-231

27. Kuder KG, Ozyurt N, Mu EB, Shah SP (2007) Rheology of fiber-reinforced cementitious composites. Cem Concr Res 37:191-199

28. Ozyurt N, Mason TO, Shah SP (2007) Correlation of fiber dispersion, rheology and mechanical performance of FRCs. Cem Concr Compos 29(2):70-79

29. Boulekbache B, Hamrat M, Chemrouk M, Amziane S (2010) Flowability of fibre-reinforced concrete and its effect on the mechanical properties of the material. Construct Build Mater 24(9):1664-1671

30. Ferrara L, Park YD, Shah SP (2007) A method for mixdesign of fiber-reinforced self-compacting concrete. Cem Concr Res 37:957-971

31. Chung DDL (2005) Dispersion of short fibers in cement. ASCE J Mat'l Civ Eng 17(4):379-383

32. Yang EH, Sahmaran M, Yang Y, Li VC (2009) Rheological control in the production of engineered cementitious composites. ACI Mater J 106(04):357-366

33. Marshall DB, Cox BN (1988) A J-integral method for calculating steady-state matrix cracking stresses in composites. Mech Mater 8:127-133

34. Li VC, Leung CKY (1992) Theory of steady state and multiple cracking of random discontinuous fiber reinforced brittle matrix composites. J Eng Mech ASCE 118(11): 2246-2264

35. Kanda T, Li VC (1999) A new micromechanics design theory for pseudo strain hardening cementitious composite. ASCE J Eng Mech 125(4):373-381

36. Lin Z, Li VC (1997) Crack bridging in fiber reinforced cementitious composites with slip-hardening interfaces. J Mech Phys Solids 45(5):763-787

37. Li VC, Wang S (2006) Microstructure variability and macroscopic composite properties of high performance fiber reinforced cementitious composites. J Probab Eng Mech 3(21):201-206

38. Bingham EC (1922) Fluidity and plasticity. McGraw-Hill, New York

39. Malek RIA, Roy DM (1991) Modeling the rheological behavior of cement pastes: a Review. Advances in cementitious materials ceramic transactions. The American Ceramic Society, Esterville, pp 31-40

40. Schleibinger Testing Systems, http://www.schleibinger. com. Accessed on 13 Aug 2009

41. Banfill PFG (1991) The rheology of fresh mortar. Mag Concr Res 43(154):13-21

42. Ferrais CF, de Larrard F (1998) Testing and modeling of fresh concrete rheology interagency report 6094, National Institute of Standards and Technology

43. Flatt R, Larosa D, Roussel N (2006) Linking yield stress measurements: spread test versus Viskomat. Cem Concr Res 36(1):99-109

44. ASTM D6910-04 Standard test method for marsh funnel viscosity of clay construction slurries

45. Roussel N, Roy RL (2005) The Marsh Cone: a test or a rheological apparatus? Cem Concr Res 35(5):823-830

46. Stang H (2003) Scale effects in FRC and HPFRCC structural elements. High performance fiber reinforced cementitious composites. In: Naaman AE, Reinhardt HW (eds) RILEM Proceedings Pro 30, pp 245-258

47. Torigoe S, Horikoshi T, Ogawa A, Saito T, Hamada T (2003) Study on evaluation method for PVA fiber distribution in engineered cementitious composite. J Adv Concr Tech 1(3):265-268

48. Ferrara L, Meda A (2006) Relationships between fibre distribution, workability and the mechanical properties of SFRC applied to precast roof elements. Mater Struct 39(4):411-420

49. Lee BY, Kim JK, Kim JS, Kim YY (2009) Quantitative evaluation technique of polyvinyl alcohol (PVA) fiber dispersion in engineered cementitious composites. Cem Concr Compos 31(6):408-417

50. Spring RS, Davidson MW (2009) Introduction to fluorescence microscopy. Nikon Microscopy U. http://www.microscopyu. com/articles/fluorescence/fluorescenceintro.html. Accessed on 6 Jun 2009

51. Li M (2009) Multi-Scale Design for Durable Repair of Concrete Structures, $\mathrm{PhD}$ Dissertation, University of Michigan

52. Yang EH, Garcez E, Li VC (2012) Development of pigmentable engineered cementitious composites for architectural elements through integrated structures and materials design. J Mater Struct 45:425-432 